\title{
LA GUERRA CIVIL EN CASTILLA Y LEÓN: ENSAYO GENERAL PARA LA DICTADURA FRANQUISTA
}

\author{
Severiano Delgado, Mari Luz de Prado y Santiago M. López
}

\section{Introducción}

La Guerra Civil española en la comunidad autónoma de Castilla y León suele quedar oculta por los poderosos focos de atracción que se presentan durante el verano de 1936 en otros puntos de la geografía española, como la revolución en Cataluña y el avance de las columnas milicianas hacia Aragón, o la concentración del ejército de África en Andalucía occidental y su avance hacia Madrid por Badajoz y Toledo. Son grandes movimientos de masas con mucho ruido y mucho dramatismo, momentos trascendentales que en su momento concitaron la atención del mundo. Junto a ellos, lo ocurrido en Castilla la Vieja y el antiguo reino de León atrajo poca atención, excepto por el hecho de que fueron varias ciudades de su territorio las que serían capitales iniciales del nuevo régimen, y escaso interés del historiador hasta tiempos recientes. Sin embargo, podría decirse que en la mente de los conspiradores que desde marzo de 1936 comenzaron a preparar el golpe de Estado, encabezados por el general Mola, las cosas tendrían que haber sido en toda España como en Castilla la Vieja: una acción fulgurante basada en la toma inmediata del poder local y la formación de columnas armadas para marchar rápidamente sobre Madrid, acompañada de una represión desmesurada, muy violenta, que paralizara por el terror al conjunto de la población, para asegurar la retaguardia. ${ }^{1}$

1. Una exposición más detallada del tema de este artículo en Delgado Cruz, S. y López GarCía, S., «Una aproximación a la Guerra Civil en Castilla y León», en Redero, M. y De LA Calle, M. ${ }^{a}$ D. (eds.), Castilla y León en la historia contemporánea, Salamanca, Universidad de Salamanca, 2008, pp. 427-486. 
Los hechos de armas en Castilla y León no pasaron por lo general de desarrollarse en siete días. A partir del 18 de julio de 1936, las fuerzas sublevadas no tardaron más de una semana en hacerse con el control de prácticamente la totalidad de la región, después de haber aplastado los escasos brotes de resistencia planteados por columnas obreras improvisadas. Los únicos enfrentamientos armados de cierta importancia se dieron en julio y agosto en el sur de las provincias de Ávila y de Segovia, relacionados con la lucha por el control de los pasos de las sierras del Sistema Central desde la Meseta norte hacia Madrid (Somosierra, Navacerrada y Guadarrama). Desde octubre de 1936 esos frentes permanecieron prácticamente inactivos hasta el final de la guerra. En el otro extremo, al norte de las provincias de León, Palencia y Burgos se formó un frente difuso con la zona gubernamental del Cantábrico que perduró hasta el otoño de 1937, cuando los nacionalistas conquistaron Vizcaya, Santander y Asturias.

Desde el punto de vista militar, las provincias de la actual Castilla y León se repartían entre tres divisiones orgánicas, dos de las cuales tenían el cuartel general en la región $6 .^{a}$ (Burgos) y $7 .^{a}$ (Valladolid). En ambas la conspiración alcanzó gran amplitud. Soria formaba parte de la 5. ${ }^{a}$ (Zaragoza) y León de la 8. ${ }^{a}$ (La Coruña), divisiones en las que también triunfó el golpe militar.

Sociedad de base agraria, en la que el latifundio coexistía con una amplia presencia del pequeño y mediano propietario agrícola, Castilla y León ofrecía un fértil campo al conservadurismo que, junto con el catolicismo clerical, ocupaba la mayor parte del espacio político, a través de los sindicatos católicos agrarios, Acción Popular y otros partidos integrantes de la CEDA. A pesar de la importancia que cobró tras el golpe de Estado, Falange Española era una organización pequeña, con muy pocos afiliados (salvo en Valladolid). El peso de la izquierda recaía en el Partido Socialista y sobre todo en la UGT, tanto en sus sindicatos urbanos como en la Federación Nacional de Trabajadores de la Tierra (es decir, en el entramado de sociedades obreras que conformaban la Casa del Pueblo), que logró una amplia implantación en el campo castellano al albur de la legislación laboral de Largo Caballero.

El lector encontrará tres partes en el presente artículo. La primera está dedicada a una somera descripción del golpe de Estado y los acontecimientos que se sucedieron al fallar el golpe de Estado e iniciarse un complejo proceso de constitución de un nuevo Estado que llevaría a Salamanca, Burgos y Valladolid a convertirse en las capitales del régimen. En la segunda parte se analiza la represión, tanto la física como la social, y en este sentido ponemos el énfasis en la represión económica, en parte porque el aparato legal y los primeros ensayos nacieron en esa región, pero también porque es uno de los aspectos menos conocidos de la represión franquista. Las conclusiones cierran el artículo. 


\section{El golpe de estado fallido y constitución del Nuevo Estado: el papel jugado por Castilla y Léon}

A partir del 18 de julio de 1936 los hechos se repiten casi punto por punto en las nueve provincias de Castilla y León, con la excepción de León, Soria y Ávila.

El jueves o el viernes anteriores al sábado 18 de julio, los militares conjurados acuartelan las tropas sin haber recibido una orden al respecto por parte del Ministerio. Normalmente la Guardia Civil de toda la provincia se encuentra concentrada en la capital correspondiente por orden del gobernador civil. El sábado por la tarde o el domingo por la mañana, al recibir la orden del general faccioso que controla la jefatura divisionaria ${ }^{2}$, los conspiradores toman el mando de la guarnición y detienen al jefe, en el caso de que éste no formara parte de la trama, así como al resto de los oficiales y soldados que se mostraran leales al Gobierno de la República.

Paralelamente, las noticias sobre el alzamiento del ejército en África hacen que los dirigentes del Frente Popular se reúnan en el Gobierno Civil para evaluar la situación. Grupos de jóvenes de la Casa del Pueblo patrullan las calles para vigilar movimientos sospechosos de las tropas. A veces se producen tiroteos entre paisanos y militares. El gobernador civil trata de averiguar la postura del jefe de la Guardia Civil en la provincia. Se declara la huelga general.

En cuanto consideran la ocasión propicia, o cuando no les queda otro remedio, los militares sacan las tropas a la calle (normalmente el domingo $19 \mathrm{o}$ el lunes 20) y, en un lugar céntrico, leen el bando de declaración del estado de guerra, redactado por el general jefe correspondiente. A continuación se dirigen a tomar el Gobierno Civil, el Ayuntamiento y la Casa del Pueblo. A menudo comienza un tiroteo con grupos obreros, más o menos enconado, más o menos prolongado en el tiempo, que termina siempre con la derrota de los obreros. Estos momentos iniciales son de gran confusión, ya que mucha gente piensa que los militares salen a la calle para defender el orden constitucional. También se da el caso de personas que son detenidas cuando desde sus pueblos se desplazaban armados a la capital provincial, respondiendo a la llamada de auxilio del Gobernador civil, que a su vez había sido detenido.

Los sublevados nombran nuevas autoridades locales: gobernador civil, alcalde, presidente de la Diputación ${ }^{3}$. En todas las provincias es nombrado un militar

2. Tanto el general Batet en Burgos como el general Molero en Valladolid fueron depuestos y detenidos por los facciosos. Tomaron el mando los generales Saliquet (Valladolid) y Ponte (Burgos).

3. El Gobernador civil de Soria logró escapar a Madrid. De los de Salamanca y Zamora sólo sabemos por ahora que fueron detenidos. Los restantes (Ávila, Burgos, León, Palencia, Segovia y Valladolid) fueron fusilados. Los Alcaldes de Burgos, Segovia y Soria fueron 
como nuevo gobernador civil, el cual llama por teléfono a todos los puestos de la Guardia Civil de la provincia y les ordena que declaren el estado de guerra, disuelvan la gestora municipal y detengan a los elementos extremistas (o sea, de izquierdas). Se ordena también la puesta en libertad de los falangistas y derechistas presos, si los hubiera.

De inmediato comienzan a formarse las columnas militares que deben partir hacia Madrid a través de los puertos de la sierra, sobre la base de los regimientos existentes en las diferentes plazas. Son formaciones mixtas de soldados de reemplazo y voluntarios civiles, mandadas siempre por oficiales profesionales. Empiezan a formarse compañías milicianas de voluntarios falangistas y tradicionalistas, que entrarán en acción poco después. ${ }^{4}$

Nada más tomar el poder en la capital de la provincia, se constituyen columnas volantes de guardias civiles y voluntarios (aquí es donde aparecen falangistas a cientos, cuando el día anterior apenas había) que recorren la provincia para imponer la nueva legalidad. Aunque los jefes militares se habían negado a dar armas a quienes querían defender el orden constitucional, ahora no tienen inconveniente en armar a miles de voluntarios civiles, muchos de los cuales se dedicarán de inmediato a sembrar el terror entre sus convecinos, con el beneplácito de las autoridades militares, civiles, judiciales y eclesiásticas.

La mayor resistencia al golpe suele darse en los lugares con mayor concentración de obreros: nudos ferroviarios, comarcas mineras, obras de pantanos o ferrocarriles, etc. Esto se debía al alto grado de sindicación que había en estas ocupaciones. Cuando la resistencia era de cierta envergadura, se enviaba contra ellos una unidad militar. Los más importantes de estos choques armados tuvieron lugar en León, tanto en la capital como en la comarca del Bierzo, sobre todo en Ponferrada. También hubo choques importantes en Sanabria, en Miranda de Ebro, en Aranda de Duero, en Béjar y en el sur de las provincias de Ávila y de Segovia.

En algunas provincias, al encontrarse los pueblos desguarnecidos por estar concentrada la Guardia Civil en la capital, numerosos alcaldes del Frente Popular organizaron patrullas armadas con hombres de la Casa del Pueblo. Pero la

confirmados en el cargo. Los de León, Palencia, Salamanca y Valladolid fueron fusilados. El Alcalde de Ávila murió en la cárcel y del de Zamora sólo sabemos por ahora que fue detenido.

4. Todas estas columnas tenían una composición muy heterogénea, variable y heterodoxa. Grupos de soldados, en núcleos normalmente no superiores a una compañía, milicianos políticos y guardias civiles y de Asalto, en una mezcla totalmente improvisada, daban al conjunto una fisonomía particular y una eficacia muy relativa, tanto en uno como en otro bando (Salas Larrazábal, Ramón, Los datos exactos de la Guerra Civil, Madrid, Rioduero, 1980, p. 157). 
aparición de la Guardia Civil o de columnas militares acababa con todo conato de resistencia.

Todo este proceso, comenzado el 18 de julio, sábado, suele estar terminado hacia el día 22, miércoles.

El caso de Soria tiene alguna particularidad, debido a que en aquella provincia no había guarnición militar, sino solamente la Caja de Recluta. Por lo visto, nadie informó a los guardias sorianos de los detalles del alzamiento, por lo que éstos en principio no hicieron nada hasta que se enteraron de manera fehaciente de que el golpe había triunfado en Navarra, Logroño y Zaragoza, por lo que no declararon el estado de guerra hasta el día 21, martes.

La situación en León fue más complicada a causa de la llegada el día 19 de dos columnas con varios miles de obreros asturianos, por lo que los militares se abstuvieron de sacar las tropas a la calle. Cuando los asturianos volvieron a casa, al tener noticia de la traición del coronel Aranda en Oviedo, los conjurados declararon el estado de guerra el lunes 20, dando lugar a fuertes enfrentamientos armados con los grupos mineros, tanto en la propia capital como en los pueblos mineros, sobre todo en Ponferrada. ${ }^{5}$

En el sur de la provincia de Ávila y en el este de la de Segovia, la intervención de columnas gubernamentales procedentes de Madrid, impidió la consolidación del golpe militar. Durante todo el mes de julio se produjeron numerosos choques entre columnas móviles de uno y otro bando. Navalperal y Cebreros, en la sierra de Gredos, fueron el centro de la resistencia republicana. En esta parte de Castilla los enfrentamientos tuvieron como objetivo el control de los principales pasos de la Meseta norte hacia Madrid: Somosierra (carretera Madrid-Burgos-Irún), Navacerrada (carretera Madrid-Segovia) y Guadarrama (carretera Madrid-La Coruña). En estos combates destacaron la columna Serrador (nacionalista), que partió de Valladolid hacia el Alto del León, la columna García Escámez (nacionalista), que partió de Pamplona para alcanzar Somosierra después de controlar Logroño y Soria, y la columna Mangada (gubernamental), que desde Madrid llegó hasta las inmediaciones de la ciudad de Ávila y se retiró sin intentar el ataque.

5. Esta columna minera, formada por orden del gobierno, tenía como destino Madrid. La noticia de su existencia se difundió a gran velocidad por toda Castilla, alentando las esperanzas de quienes intentaban defender el orden constitucional por toda la región. La primera parte de la columna partió en el expreso diario Gijón-Madrid que salía de Gijón a las 19:30h, y llegó a Madrid a primeras horas de la mañana del domingo 19. La segunda parte, formada por un tren especial y varios camiones, salió horas después y llegó a León el domingo 19 a primera hora. Como Valladolid ya estaba controlado por los golpistas, tomaron el camino de Zamora, pero en Benavente se dieron la vuelta y regresaron a Asturias por Ponferrada. 
A los dos días del alzamiento era ya evidente que los planes de Mola habían fallado en la Península: el golpe había sido aplastado en la 1. ${ }^{a}$ División (Madrid) y en la 4. ${ }^{a}$ (Barcelona). En la 3. ${ }^{a}$ (Valencia) la mala preparación del complot convirtió el golpe en un simple amago. En la 2. ${ }^{a}$ División (Sevilla), los golpistas sólo habían logrado controlar algunos islotes, como Sevilla y Granada. La 5. ${ }^{a}$ (Zaragoza) había conseguido controlar las tres capitales aragonesas, pero debía prepararse para el ataque que se avecinaba desde Cataluña.

Los mejores resultados se habían dado en las divisiones en las que Mola había podido preparar mejor la conspiración y los golpistas tenían mayor apoyo social: la 6. ${ }^{a}$ (Burgos), la 7. ${ }^{a}$ (Valladolid) y la 8. ${ }^{a}$ (La Coruña). No obstante, en la 6. ${ }^{a}$ División, las provincias de Guipúzcoa, Vizcaya y Santander habían quedado en manos del Gobierno. En la 8. ${ }^{a}$, el golpe había triunfado en las cuatro provincias gallegas, pero en la comandancia exenta de Asturias sólo Oviedo se había unido a la sublevación. El general Mola, en consecuencia, sólo contaba plenamente

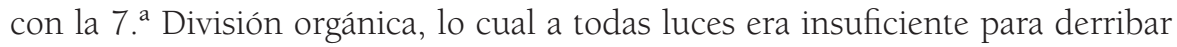
al Gobierno de la República.

Las divisiones $6 .^{a}, 7 .^{a}$ y $8 .^{a}$ aportaron a la sublevación unos 16.000 hombres de unidades regulares, incluyendo todas las armas y servicios, mientras que la 2. a División, la 5. a y las comandancias de Canarias y Baleares aportaron otros $16.000^{6}$. Al mismo tiempo, las provincias de Castilla la Vieja, Galicia y Navarra aportaron varios miles de voluntarios políticos (en su inmensa mayoría falangistas y requetés) al ejército sublevado. Las unidades milicianas desempeñaron siempre un papel auxiliar del ejército regular, pero en los momentos iniciales de la guerra su participación fue decisiva en la lucha por los puertos del Sistema Central, aportando unos 11.000 hombres a ese frente ${ }^{7}$, y en fijar el frente norte de Álava, Burgos, Palencia y León. ${ }^{8}$

La columna lanzada desde Pamplona, mandada por García Escámez, perdió un tiempo precioso ocupándose de la «pacificación» de La Rioja y de Soria.

6. Alpert, El ejército republicano en la Guerra Civil, París, Ruedo Ibérico, 1977, pp. 342-343. Se trata del personal efectivo en los cuarteles, no la plantilla teórica.

7. Martínez Bande, J. M., La marcha sobre Madrid, Madrid, San Martín, 1982, p. 59.

8. Véase CaSAS de la Vega, R., Las milicias nacionales en la Guerra de España, Madrid, Editora Nacional, 1974. Este autor estudia solamente las fuerzas encuadradas en la Jefatura Nacional de Milicias de FET y de las JONS, que actuaron normalmente en el frente de batalla, pero no se puede pasar por alto el hecho de que estas unidades también tuvieron una importante presencia en las labores de represión, al igual que los grupos irregulares de falangistas, requetés y derechistas en general, que en los primeros meses de la guerra actuaron como escuadrones de la muerte. Los piquetes represivos llevaron a cabo las tareas más sucias de «pacificación del territorio» que ni el Ejército ni la Guardia Civil querían llevar a cabo por sí mismos. 
Finalmente fue detenida en Sigüenza (Guadalajara). Las organizadas desde Burgos y Valladolid para hacerse con el control de los puertos de Somosierra y de Guadarrama, fueron detenidas por las fuerzas gubernamentales, que a su vez eran también columnas mixtas improvisadas de milicianos, militares y fuerzas de seguridad. En los primeros días de agosto los combates fueron muy violentos, pero a partir del día 10 el frente comenzó a estabilizarse. Los nacionalistas conservaron el control del Alto del León, pero la prevista marcha sobre Madrid a partir de Navarra, Valladolid y Burgos había quedado detenida.

Las columnas de Mola pusieron de manifiesto sus propias limitaciones: por un lado, eran demasiado exiguas como para lanzarse a la ocupación de Madrid; por otro, quedaron agotadas por la resistencia encontrada. Resultaba absurdo plantearse un ataque sobre Madrid con unos cuantos miles de hombres, muchos de ellos milicianos civiles, exhaustos por largos días de combate, debiendo vencer una fuerte resistencia en la sierra y sin tener la posibilidad de recibir refuerzos. Las columnas de Mola, que en ningún momento pudieron equipararse a una gran unidad tipo brigada, carecían de reserva, tanto humana como material, y de unidades de apoyo logístico, sanitario, etc. Así las cosas, el general Mola quedó a expensas de lo que hiciera el ejército del sur, dirigido por el general Franco, que avanzaba rápidamente por la carretera de Extremadura, después de haber tomado Mérida y Badajoz entre el 11 y el 15 de agosto. La figura de Mola declinaba, mientas Franco empezaba a perfilarse como el general decisivo del bando rebelde, puesto que estaba al frente de las únicas tropas profesionales existentes en el Ejército español, y además había establecido en poco tiempo importantes relaciones con la Alemania nazi y la Italia fascista, que le habían prestado auxilio aéreo y naval para cruzar el estrecho de Gibraltar en los primeros días de la guerra. Franco incluso había conseguido que el Gobierno de Portugal permitiera que camiones militares españoles circularan por suelo portugués para llevar municiones del ejército del sur al del norte, antes de que la toma de Mérida permitiera unir las dos zonas sublevadas.

Por el contrario, a Mola se le complicaban las cosas. En el norte de la Península se habían formado dos poderosos focos de atracción: Oviedo y Bilbao. La 8. ${ }^{a}$ División se estaba centrando en el control del territorio gallego y el auxilio a los sublevados que estaban cercados en la capital asturiana. A la vista de la fuerte resistencia encontrada en las sierras centrales, Mola asignó nuevos objetivos a la 6. ${ }^{a}$ División: ocupar la frontera francesa (Irún), fijar el frente al norte de Álava y Burgos, y auxiliar a otras zonas sublevadas, como Aragón. A comienzos de septiembre Mola, basándose en las milicias carlistas, lanzó una ofensiva contra Guipúzcoa, logrando ocupar Irún el 4 de septiembre y San Sebastián el 16. La ocupación de Irún resultó decisiva para el desarrollo posterior de la guerra, por- 
que dejó la zona norte republicana completamente cerrada por tierra. El frente norte quedó estabilizado durante varios meses, sin más actividad que la habitual de la guerra de posiciones, hasta que en abril de 1937 las fuerzas nacionalistas lanzaron un ataque contra Vizcaya, ocupando Bilbao el 19 de junio, que continuó hasta la ocupación total de Asturias en octubre de ese mismo año. Una vez superados estos escollos por Mola, había que plantearse formar un nuevo Estado, ya que la toma del poder republicano era imposible.

Castilla la Vieja ofrecía a los sublevados una excelente plataforma para instalar los órganos de mando de la sublevación hasta que cayera Madrid, cosa que se preveía inminente. Todas las provincias de la región estaban bien controladas y, excepto el molesto pero poco amenazante frente norte, no había actividad bélica cerca de las principales ciudades. El 24 de julio de 1936 se constituyó en Burgos la Junta de Defensa Nacional, presidida por el general Cabanellas. La Junta tuvo poca actividad política, puesto que se contemplaba como un organismo provisional. Era más bien el embrión del directorio militar previsto en los planes de Mola. Sus actos políticos más importantes fueron el bando declarando el estado de guerra en todo el territorio nacional (28 de julio) y la elección de Franco como Jefe del Estado, con la consiguiente creación de la Junta Técnica del Estado, el 1 de octubre de 1936, con sede en Burgos y presidida por el general Dávila.

La elección de Franco como Jefe del Estado y la creación de la Junta Técnica suponían la creación explícita de un nuevo Estado, sobre bases jurídicas que ya no eran la Constitución de la República. Era una ruptura definitiva con el sistema republicano. A pesar de ello, Franco no dio el paso de crear ministerios, sino comisiones $^{9}$, cuyos presidentes eran técnicos sin peso político. Con todo, pronto Burgos empezó a nutrirse de los nuevos funcionarios y personal que debía ocuparse de poner en marcha un Estado paralelo al republicano.

Por su parte, el 6 de octubre se creó en Valladolid el cargo de gobernador general con sede en dicha capital. Para el cargo se designó al general Fermoso, quien lo ocupó hasta principios de noviembre de 1936, cuando fue reemplazado por el general Valdés. La figura del gobernador general ya había sido utilizada anteriormente por el Gobierno de la República en ocasiones excepcionales, como los sucesos de octubre de 1934 en Asturias y León. El gobernador general venía a ser un super-gobernador civil que asumía la dirección de todas las administraciones públicas en una provincia o varias, así como la jefatura superior de las fuerzas de orden público. Valladolid jugó desde el principio el papel de la capital

9. Norma general para el funcionamiento de la Junta Técnica del Estado, Boletín Oficial del Estado de 6 de octubre de 1936. Los ministerios del Nuevo Estado fueron creados por ley de 30 de enero de 1938. 
política del nuevo régimen. En ella se concitaban las nuevas fuerzas políticas, en especial Falange, que irían dando lugar a la constitución del partido único, tan característico de las dictaduras del momento, y también de Auxilio Social y en buena medida la estructura de sindicato único, es decir la cara más social del nuevo régimen. En Salamanca, por su parte, se instaló el Cuartel General del Generalísimo, que hizo las funciones de gobierno militar-político efectivo de la zona facciosa hasta que Franco trasladó su residencia a Burgos en octubre de 1937. La ciudad operó como un magnífico escaparate para dotar a los insurgentes de la parafernalia estética y de propaganda ideológica. Además se convirtió en la perfecta retaguardia y sede, por tanto, de las delegaciones internacionales y los mandos militares alemanes e italianos. Las tres ciudades tuvieron una actividad frenética para ir conformando el nuevo Estado; consiguientemente, se vieron pobladas de refugiados, nuevos funcionarios, los nuevos miembros de los movimientos políticos que desembocarían en el partido único y, por supuesto, militares españoles a los que se sumaban las tropas de las naciones aliadas con los insurgentes.

\section{La represión}

La toma del poder por los sublevados vino acompañada desde el primer momento por una represión de enorme virulencia que en modo alguno respondía a una resistencia al golpe que no se dio en ningún lado, salvo en casos excepcionales, como hemos visto. La represión desencadenada por los sublevados estuvo perfectamente dirigida para conseguir dos objetivos simultáneos: paralizar a la población por el terror y neutralizar a la mayor cantidad posible de enemigos políticos.

La represión tuvo tres niveles: la liquidación física, la cárcel y la represión económica. La liquidación física se llevó a cabo, en un primer momento, mediante las ejecuciones extrajudiciales que convencionalmente se han dado en llamar paseos: un grupo de hombres, normalmente de fuera del pueblo, a menudo con camisa de la Falange, y acompañados a veces por un guardia civil, se presentaban en un pueblo con una lista de hombres (casi nunca mujeres) y se los iban llevando de sus casas. Cuando el camión se alejaba, los familiares comenzaban la peregrinación en busca de los detenidos: la cárcel, la comisaría, los cuarteles militares, el cuartel de Falange... A veces, los detenidos aparecían en la cárcel, pero otras eran encontrados en las cunetas de los caminos o en algunos sitios específicos, que por alguna razón los irregulares habían elegido para ejecutar a sus víctimas. Otras veces de los detenidos no se ha vuelto a saber nada. La mayor parte de las víctimas de este tipo de ejecución no han sido inscritas en ningún registro oficial.

Otra forma de liquidación física eran las sacas de la cárcel. De forma similar al paseo, una fuerza armada, con mayor o menor presencia de falangistas y guardias civiles, se presentaba en la cárcel con la orden de entrega de los hombres 
enumerados en una lista, firmada por el gobernador civil o por el comandante militar de la plaza, oficialmente para trasladarlos a otra prisión. Después, los sacados eran ejecutados en los lugares de costumbre, pero sin dar cuenta a la familia, que normalmente se enteraba de lo sucedido cuando iba a visitar a su allegado. Algunas de estas víctimas han sido inscritas en registros oficiales, cuando la familia lograba encontrar el cadáver, pero muchas han quedado sin registrar.

La tercera forma de eliminación física fueron las sentencias emanadas de los consejos de guerra, por las que se condenaba a muerte al encausado mediante la ficción legal de aplicarle el delito de rebelión militar. A los tribunales militares les bastaba con aplicar los bandos de declaración del estado de guerra emitidos por los generales Saliquet y Ponce el 19 de julio, o el emitido el 28 de julio por la Junta de Defensa Nacional extendiendo el estado de guerra a todo el territorio nacional. Posteriormente, se perfeccionaría el mecanismo represor con el decreto de 1 de noviembre de 1936, regulando el procedimiento a seguir en los procesos sumarísimos. Todas las víctimas de fusilamiento por sentencia de consejo de guerra fueron inscritas en el registro civil de la localidad en la que murieron, normalmente la capital de la provincia.

El segundo método para el control de la población fue la detención en masa. Las prisiones de la región se llenaron a rebosar desde los primeros momentos con miles de personas vinculadas de una forma u otra al Frente Popular. Incluso se habilitaron lugares de detención irregulares, como las cocheras del tranvía en Valladolid, y campos de concentración como el de Miranda de Ebro, entre otros muchos. El hacinamiento y la falta de salubridad de las prisiones provocaron la muerte de grandes cantidades de presos.

Las víctimas de la represión eran fáciles de localizar: alcaldes y concejales del Frente Popular, dirigentes de los sindicatos y de las sociedades obreras, socialistas, comunistas, anarquistas, republicanos liberales, masones y cualquier persona que se hubiera significado en las filas del republicanismo o de la izquierda. Un sector muy castigado fue el de los maestros, de los cuales varios cientos encontraron la muerte. Entre el 20 y el 25\% de los maestros de la región fueron expulsados del magisterio o sufrieron algún tipo de sanción.

Los últimos estudios sobre la represión en Castilla y León han arrojado 8.300 víctimas mortales identificadas, que podrían ascender hasta 15.000 en toda la región. ${ }^{10}$ El número de personas que sufrieron prisión o sanción económica es muy superior, aunque de momento no es posible aventurar una cifra.

10. La obra colectiva Testimonio de voces olvidadas, coordinada por Enrique BERZAL DE LA ROSA, León, Fundación 27 de Marzo, 2007, ofrece la visión más completa y actualizada sobre la Guerra Civil y la represión en Castilla y León. 
La tercera forma de represión fue la económica, y aquí lo que sucedió en Salamanca fue en muchos aspectos paradigmático de lo que acaecería en el resto de las provincias castellano-leonesas y, por extensión, en las provincias que se irían paulatinamente quedando bajo dominio insurgente $e^{11}$.

La represión económica se aplicó por diferentes vías: las incautaciones y requisas, las multas y la imposición de cuotas contributivas canalizadas a través del proceso recaudador. La represión física fue acompañada, la mayoría de las veces, de la represión económica y las incautaciones fueron la expresión directa de esa doble represión. La legislación emanada de la Junta de Defensa Nacional, con sede en Burgos, dispuso en un principio la incautación de vehículos y medios de comunicación de cualquier clase ${ }^{12}$, a éstos le siguieron las incautaciones mineras y las que amparó el decreto del 13 de septiembre de 1936 por el que se declaraban ilegales a los partidos y agrupaciones del Frente Popular ${ }^{13}$, convirtiéndose el Estado en dueño y beneficiario de las incautaciones. Posteriormente, la Junta Técnica del Estado ${ }^{14}$ reguló la incautación de bienes de dichas entidades políticas, tanto los bienes muebles como los inmuebles, estableciendo la responsabilidad civil de cuantos se hubieran opuesto al Movimiento Nacional. La Comisión Central y las provinciales creadas al efecto, se encargarían de instruir los expedientes y de administrar los bienes incautados. Posteriormente, un general de División determinaría la responsabilidad del encausado y fijaría la cantidad que debía satisfacer o, en todo caso, el embargo de los bienes. Por lo general, cuando se abría el expediente de depuración, se ordenaba la ocupación preventiva de sus bienes.

Así ocurrió en todas las provincias castellano-leonesas. Los desafectos a la causa nacional fueron objeto de la represión económica y a partir de enero de 1937 los boletines oficiales se ocuparon de publicar de forma periódica las relaciones de expedientados y sancionados sujetos al embargo de bienes, así como las notificaciones y requisitorias, que continuarían una vez acabada la guerra. En Salamanca, la Comisión Nacional de Incautación de Bienes llegó a tramitar 566 expedientes de personas procedentes de 109 municipios salmantinos y la canti-

11. El profesor J. M. Palomares Ibáñez en su libro La Guerra Civil en Palencia. La eliminación de los contrarios, Palencia, Ediciones Cálamo, 2002, p. 59, señala que «pocas novedades respecto de otras poblaciones percibimos en el caso palentino que ofrece iniciativas gemelas a las adoptadas simultáneamente en las provincias vecinas». Lo mismo se puede decir del discurrir de las retaguardias salmantina, vallisoletana o segoviana, todas ellas objeto también de investigación.

12. Decreto n. ${ }^{\circ}$ 14, firmado en Burgos por el general Miguel Cabanellas el 28 de julio de 1936, se publicó en el B. O. J. D. N. el 30 de julio de 1936.

13. Decreto n. ${ }^{\circ} 108$, B.O.J.D.N., 16-9-1936, n. ${ }^{\circ} 22$.

14. Decreto-Ley de 10 de enero de 1937. 
dad de dinero requisado y rectificado superó los cinco millones de pesetas. En la provincia de Burgos, desde 1937 hasta 1943 se instruyeron un total de 1.004 expedientes y en Soria $471^{15}$.

Las incautaciones y requisas se convirtieron, pues, en una práctica corriente desde el inicio de la guerra como medio para obtener recursos extraordinarios y como mecanismo represor de los contrarios. Sin embargo, para financiar la contienda los insurgentes necesitaron no sólo de los tributos habituales sino también de las suscripciones e impuestos especiales, configurando de ese modo el proceso recaudador y utilizándolos como vehículos de control y represión de la población ${ }^{16}$. Los insurgentes, desde el inicio de la guerra, promovieron «campañas patrióticas» para recoger fondos en metálico o, en su defecto, recursos en especie; sin embargo, como las entregas voluntarias no fueron ni tan rápidas ni tan cuantiosas como ellos esperaban, presionaron a la población para que contribuyera con cantidades asignadas a través de «saludos-invitaciones», poniendo de manifiesto desde el inicio el dirigismo y la coacción de las nuevas autoridades. Las cantidades obtenidas acabaron engrosando las distintas suscripciones abiertas a lo largo de toda la guerra. No obstante, la insuficiente recaudación para cubrir las necesidades que se iban presentando obligó a las autoridades a establecer el reparto contributivo a través de cuotas «guiadas» entre los vecinos, con lo que adquirieron un carácter obligatorio que apenas se diferenciaron de los impuestos. Las Comisiones Oficiales dieron paso a las Comisiones provinciales y locales, que serían las encargadas de la apertura y desarrollo del proceso suscriptor. Las autoridades, en especial el gobernador civil, se ocuparon del seguimiento y control de todo el proceso recaudador y los centros de poder, Gobierno Civil, Ayuntamiento y Diputación Provincial, en los principales impulsores y depositarios de la ayuda.

15. Rilova Pérez, I., Guerra Civil y violencia política en Burgos (1936-1943), Burgos, Dossoles, 2001, p. 147. El profesor J. M. Palomares afirma que la comisión provincial de incautaciones publicó en el Boletín Oficial de la Provincia las relaciones de personas objeto de incautación; entre esas relaciones entresaca la de los 62 expedientados de Nava del Rey (BOPVA, 25-1-1938, p. 70) en La guerra civil en la ciudad de Valladolid. Entusiasmo y represión en la «capital del alzamiento», Valladolid, Ayuntamiento de Valladolid, 2001, p. 160.

16. Tres capitales coordinaron el proceso recaudador: en Burgos, tras la constitución de la Junta Técnica del Estado, las autoridades establecieron un Servicio de Hacienda. Previamente y en la sucursal del Banco de España de esta capital se había constituido el Banco de España de la zona nacional y el Laboratorio del Oro para la transformación del oro procedente de la Suscripción Nacional. Desde Valladolid, el gobernador general se encargaría de dar órdenes a los respectivos gobernadores civiles para coordinar y hacer un seguimiento del proceso recaudador. Y, por último, a finales de septiembre de 1936, Franco asumió la jefatura máxima y estableció en Salamanca el Cuartel General. 
Mientras se abrían suscripciones con carácter oficial y para todo el territorio dominado, surgieron otras que respondían a iniciativas locales para cubrir necesidades concretas ${ }^{17}$. No obstante, a mediados de agosto, para ordenar y encauzar el proceso suscriptor se creó la Suscripción Nacional ${ }^{18}$. Ésta sirvió para institucionalizar la «campaña patriótica» y para atraer recursos con los que constituir el Tesoro Nacional. Simultáneamente y mientras los particulares entregaban oro, divisas y monedas antiguas, se siguieron abriendo nuevas suscripciones en todo el territorio bajo dominio insurgente. La reticencia a la entrega de donativos o cuotas asignadas por parte de la población, se venció con la presión y la coacción. Para ello se consultó a los gobernadores civiles las medidas sancionadoras que debían tomar contra los más reacios a la participación ${ }^{19}$. Los ciudadanos utilizaron su participación como aval justificativo de su apoyo a la causa o como medio para eludir la represión. Y como la Suscripción Nacional no fue suficiente para asegurarse la liquidez y el control de la población, la Hacienda de Burgos dispuso de la parte de los rendimientos tributarios de su zona más los derivados de nuevas figuras impositivas, como la que estableció la detracción de haberes de funcionarios $^{20}$. Con este impuesto se consiguió un doble objetivo: asegurarse la recaudación de forma periódica y fija que no se había logrado con las suscripciones y controlar a un sector importante de la población, algunos de cuyos miembros ya habían sido depurados o represaliados. En esa misma línea y para garantizarse la liquidez permanente y la financiación del vasto entramado asistencial se crearon impuestos, personales y de consumo, con destino al Fondo de Protección Benéfico-Social21. El 30 de octubre de 1936 se estableció el impuesto

17. Unas suscripciones fueron dirigidas a recaudar fondos con destino a las fuerzas armadas locales, ejército y milicias, otras para adquirir armamento y apoyo logístico o para atender a los heridos llegados del frente. En las provincias castellanas se rivalizó con la apertura de suscripciones destinadas a financiar aviones con el nombre de la ciudad, como ocurrió, entre otras, en Palencia, Salamanca o Valladolid y en todas las provincias se generalizaron los homenajes, las celebraciones con ocasión de la toma de las ciudades o el apoyo a los soldados en el frente por Navidad a través del aguinaldo pro combatiente o aquéllas destinadas a la recogida de fondos con los que auxiliar a las poblaciones «liberadas». Todas ellas se acompañaron de la correspondiente suscripción.

18. Orden de 19 de agosto de 1936.

19. Para el detalle de lo ocurrido en Salamanca, véase la tesis: Prado Herrera, M. ${ }^{a}$ de la Luz de, La contribución popular a la financiación de la Guerra Civil: Salamanca, 1936-1939, Salamanca, Universidad de Salamanca, 2006.

20. Decreto n. ${ }^{\circ} 69$ de la Junta de Defensa Nacional firmado en Burgos el 26 de agosto de 1936 y publicado en el Boletín Oficial el 30 de agosto.

21. Orden del 29 de diciembre de 1936 del Gobierno General. BOE, 3 de enero de 1937. 
del Plato Único ${ }^{22}$ y posteriormente el lunes sin postre ${ }^{23}$, de aplicación en todo el territorio sometido; por las mismas fechas inició su andadura en Valladolid Auxilio de Invierno, convertido en Auxilio Social en mayo de 1937. Para recaudar fondos con los que financiar este entramado asistencial, se utilizaron, entre otros, la Ficha Azul y las Cuestaciones, y ambas consiguieron aunar en uno sólo los mecanismos suscriptor e impositivo. Por último, el Subsidio Pro-combatiente se estableció para recaudar fondos con los que auxiliar a los familiares de los soldados que estaban en el frente $e^{24}$.

Desde la entrada en vigor de estos impuestos los gobernadores civiles vigilaron la falta de celo de los ciudadanos y amenazaron y sancionaron con multas de distinta cuantía a todos aquellos que se negaran a contribuir. Tampoco descuidaron la publicación de las circulares con los nombres de los morosos y las cantidades asignadas en los boletines oficiales de las respectivas provincias y en la prensa local ${ }^{25}$. Las relaciones nominales de los contribuyentes se contrapusieron a las «listas negras» con los nombres de los rebeldes que se habían negado a colaborar, marcando de ese modo la divisoria entre patriotas y antipatriotas. A la represión se unió el escarnio público y las resistencias, cuando las hubo, fueron doblegadas por la cúpula que detentaba el poder y sus colaboradores, comunicando previamente al Gobierno Civil quiénes eran los protagonistas de dichas resistencias y las medidas coactivas que se debían aplicar. Así ocurrió en todas las provincias castellano-leonesas de las que tenemos investigaciones al respecto ${ }^{26}$.

22. La orden que creaba el Plato Único fue firmada por el general Francisco Fermoso, gobernador general residente en Valladolid. BOE n. ${ }^{\circ} 20$ del 3 de noviembre de 1936. El gobernador general Luis Valdés Cavanilles, será quien dicte las instrucciones, precisando la forma de efectuar la recaudación a través de la Orden del gobierno general, BOE, n. ${ }^{\circ} 28$, 12 de noviembre de 1936. Los gobernadores civiles respectivos se encargarían de aplicar dichas instrucciones en cada provincia. Las Juntas Provinciales de Beneficencia, de las que dependería el Negociado del Plato Único, controlarían y supervisarían todo lo referente a este impuesto.

23. En el artículo $3 .^{\circ}$ de la Orden de 16 de julio de 1937 se estableció que a partir del mes de agosto se creaba el Día Semanal sin postre.

24 Sería un impuesto de tipo indirecto, que gravaba determinadas formas de consumo. Decreto n. ${ }^{\circ} 174$, BOE, n. ${ }^{\circ} 83,9-1-1937$.

25. En Salamanca se publicaron periódicamente las listas de morosos tanto en el Boletín Oficial de la Provincia como en la prensa local: La Gaceta Regional y El Adelanto. Lo mismo ocurrió en otras capitales, como ha señalado J. M. PALOMARES IBÁÑEZ para Palencia y Valladolid en sus respectivas obras ya citadas, pp. 68 y 62, respectivamente.

26. Al igual que en Salamanca, los gobernadores civiles de Valladolid, García de Diego y Aspe, siguieron en corto los avatares de la recaudación sancionando a quienes pretendieran eludir este impuesto y atemorizando a todos aquellos poco o nada entusiastas de la contribución. Palomares Ibánezz, J. M., La guerra civil en la ciudad de Valladolid..., p. 61 y Palomares IbÁNezZ, J. M, La Guerra Civil en Palencia..., p. 67. 
Por último, desde el inicio de la guerra se obligó a la población a manifestarse, a participar en ceremonias civiles y religiosas, en homenajes a las autoridades relevantes y en festejos con ocasión de los triunfos militares. Los alcaldes, junto con sus colaboradores, se preocuparon de vigilar la participación de los vecinos en dichos actos y de comunicárselo al gobernador civil. La negativa de éstos será sancionada, por lo que las multas por desafección al nuevo orden se convertirán en otra forma más de extracción económica y de extorsión ciudadana.

En definitiva, los insurgentes desde la toma de poder ejercieron un control absoluto de la población y, a través del proceso recaudador, una forma de represión económica con la utilización de medios coactivos para obligar a la población a contribuir. Las incautaciones fueron la expresión directa de la represión política y económica.

\section{Conclusiones}

La guerra y la represión en Castilla y León posiblemente sea la menos estudiada de toda España. Desde el punto de vista militar, no encontramos ninguna de las grandes batallas y frentes de guerra. Por el lado de la represión, tampoco ésta es comparable a lo acontecido en otras regiones, como Extremadura o Andalucía. A su vez, los historiadores locales y los movimientos cívicos no han sido tan activos como los de Cataluña, País Vasco y Navarra, donde desde la vuelta a la democracia la labor de reconstrucción histórica y recuperación de la memoria han sido intensas. Sin embargo, lo que sucedió en Castilla y León es clave para entender el golpe, el terror y el modelo de dictadura que se extendería por todo el territorio. En muchos sentidos ciudades como Valladolid, Salamanca y Burgos fueron los laboratorios del nuevo régimen. En esta región fue donde los golpistas tuvieron que pensar y poner en práctica su nuevo modelo de sociedad: la dictadura franquista. En esta región se instituyeron los nuevos tribunales, los primeros asesinatos ligados a mantener bajo el terror a la población, las variopintas formas de represión, los nuevos valores, símbolos y discursos, etc. Fue en Castilla y León donde el golpe militar, al fracasar en Madrid, se convirtió en la máquina de terror que dio paso a la dictadura.

La dictadura supo inculcar un sentimiento en la sociedad castellano-leonesa de que había sido proclive a «la restauración del orden». Valladolid, Burgos y Salamanca aparecían como ciudades cuyas poblaciones habían apoyado desde el primer momento el golpe, sociedades donde no había habido guerra y habían sido «fieles» a los valores del orden y la paz social. Ello ocultaba una realidad que en los últimos años, y al calor de los movimientos de recuperación de la memoria, se ha revelado como salvaje, que diría Unamuno, y aleccionadora, ya que nada de lo que iba a ir sucediendo en el resto de España no se había dejado de probar antes en esta región. 